\title{
TURISMO COMO FATOR ECONÔMICO PARA A DINÂMICA DO COMÉRCIO INFORMAL DAS LOCALIDADES DE AREMBEPE E IMBASSAÍ.
}

\author{
Luiz Felipe Silva de Sant'ana ${ }^{1}$, Telma Maria Sousa dos Santos ${ }^{2}$ \\ 1. Bolsista PROBIC/UEFS, Graduando do Curso Licenciatura e Bacharelado em Geografia, Universidade \\ Estadual de Feira de Santana, e-mail: 1ype.1993@ hotmail.com \\ 2. Orientador, Departamento de Ciências Humanas e Filosofia, Universidade Estadual de Feira de Santana, e- \\ mail: telmaarq@yahoo.com.br
}

PALAVRAS-CHAVE: Turismo, Comércio informal, Impacto, Ambulante

\section{INTRODUÇÃO}

O turismo é uma prática social investigada através de pesquisas em diversas áreas de estudo, dentre elas, a geografia. Nesta ciência, são analisados os impactos e repercussões da atividade turística para a organização do espaço geográfico. Nas teorias que relacionam turismo e geografia, esta atividade é caracterizada por ter o espaço geográfico como principal objeto de consumo (CRUZ, 2001). Para além, é uma atividade que contribui de modo significativo para a geração de divisas financeiras no Brasil, se encontrando em franca ascensão no país. No ano de 2012, houve através da mesma uma receita de seis bilhões de dólares (MINISTÉRIO DO TURISMO, 2012), atestando a sua importância para a economia nacional. O turismo promove um aumento da circulação de pessoas nos espaços destinados à atividade. Com este aumento, setores econômicos como o de comércio (formas e informais) e o de serviços, para além do desenvolvimento de atividades no setor de comercio informal, tendem a ter um crescimento da demanda dos seus produtos. A atividade turística pode levar a um maior desenvolvimento econômico nos espaços geográficos em que se insere, além de possibilitar modificações na infraestrutura urbana das áreas receptoras, com o aparecimento de equipamentos que proporcionam ao turista uma melhor receptividade. A finalidade central desse plano de trabalho é "Analisar como o turismo nas localidades de Arembepe (situada no município de Camaçari) e Imbassaí (situada no município de Mata de São João), localidades de Arembepe e Imbassaí no Litoral Norte da Bahia contribui para a dinamização do comércio informal", onde o turismo faz parte da economia urbana. A pesquisa pretende investigar como a atividade turística exerce influência na dinamização no comércio informal local das localidades estudadas, podendo sinalizar ainda para os períodos de maior incremento e demanda por produtos e serviços, vinculadas a está atividade. Essa proposta é parte integrante do projeto de pesquisa Turismo, Planejamento e Urbanização: uma investigação sobre as localidades de Arembepe e Imbassaí no Litoral Norte da Bahia, e deverá contribuir para a ampliação do acervo do Grupo de Pesquisa Espaço, Turismo e Ambiente (GETAM), ao qual se vincula. Esta pesquisa estabeleceu uma relação direta entre turismo e geografia, ao passo em que investiga os impactos da atividade no espaço geográfico, podendo contribuir para demais pesquisas a serem desenvolvidas nos campos da Geografia do Turismo e Geografia Econômica, bem como com temáticas diversas nas localidades estudadas. Para além, pode sinalizar para problemas econômicos vividos pelas populações locais, o que ressalta a sua importância para o desenvolvimento local das áreas estudadas.

\section{MATERIAL E MÉTODOS OU METODOLOGIA (ou equivalente)}

A metodologia deste trabalho é de cunho qualitativo, justificada pela oportunidade de compreender o espaço a ser investigado, obtendo informações através de uma abordagem 
mútua entre investigador e sujeitos da pesquisa, enriquecendo a pesquisa com relatos valorizando o problema de investigação. O caráter descritivo da pesquisa está pretenderia demonstrar através dos fatos observados e registrados a dinâmica do comércio informal nas localidades de Arembepe e Imbassaí, sem que o pesquisador interfira neles, utilizando-se de abordagem direta de através da aplicação de questionários com os sujeitos pesquisados (nesse caso os vendedores ambulantes), no qual as informações cedidas foram de muita importância para a realização da discussão do trabalho. Para a confecção da pesquisa foi realizada inicialmente através da leitura e fichamento em gabinete (em meios bibliográficos e digitais) de textos que relacionassem a tema proposto no Plano de Trabalho, auxiliando a elaboração de um referencial teórico prévio utilizando-se de referência as palavras chaves do plano de trabalho da pesquisa, palavras estas como: Turismo, Comércio informal, Impacto, Ambulante. Nesse primeiro momento foram utilizados textos de CACCIAMALI (1983), CORREA (1989), TOMAZINI (1995), LAGE (1996), ANDRADE (1998), CRUZ (2003,2007), FURTADO (2004), SANTOS (2013) entre outros. Outro momento de fundamental importância para o desenvolvimento da pesquisa foram os trabalhos em campo. Em trabalhos de geografia, a pesquisa de campo é enquadrada como um processo crítico e analítico, no qual procurase estabelecer uma relação entre o objeto pesquisado e o fenômeno, com a elaboração de questionários e entrevistas para um melhor aprimoramento na coleta de dados, contribuindo assim para uma melhor apreensão do tema pesquisado (Marconi apud Andrade,1999).Durante o período da pesquisa foram realizados dois trabalhos de campo, o primeiro no período de alta estação, de grande movimentação turísticas nas localidades, no mês de janeiro, onde o principal objetivo estava voltado ao reconhecimento dos sujeitos de pesquisa, coletas de imagens e informações prévias através de conversas informais com alguns ambulantes, turistas e moradores locais. A segunda pesquisa em campo seria utilizada para a aplicação de questionários com os sujeitos da pesquisa, que não ocorrerá devido ao período de baixa estação turística. Em vista disso, o caráter exploratório da pesquisa, que pretendia analisar as contribuições da atividade turística para o incremento e dinamização do comércio informal nas localidades de Arembepe e Imbassaí, ambas situadas no Litoral Norte da Bahia, além de verificar as ações do poder local para o fomento do comércio das localidades estudadas e a atuação dos comerciantes para o desenvolvimento do comércio das mesmas não foram executadas. Essa etapa foi prejudicada principalmente pela falta de assistência para o transporte por parte da universidade devido a cortes orçamentais. Logo, as informações encontradas em campo não são suficientes para a realização de uma discussão contundente. Os campos realizados não foram suficientes para as coletas de dados através de questionários, consequentemente afetando a discussão e levantamento de informações sobre o tema principal da pesquisa: o comércio informal. Entretanto os resultados e discussões do trabalho estão votados pincipalmente a abordagens teóricas sobre o tema na localidade de Arembepe, onde, a mesma obteve maiores informações que a localidade de Imbassaí, pois os objetivos não foram contemplados. A etapa final da pesquisa se direcionou para a elaboração do texto final, onde está inserido a análise dos poucos dados coletados através de diálogos com os sujeitos da pesquisa, o texto final (relatório técnico final), articula os 
conhecimentos teóricos encontrados na pesquisa bibliográfica juntamente com as informações coletadas na pesquisa em campo

\section{RESULTADOS E/OU DISCUSSÃO (ou Análise e discussão dos resultados)}

Nas localidades estudadas assim como em muitas outras situadas na Região do litoral norte do estado da Bahia a atividade turística não se configura somente como uma atividade econômica, mas também como uma prática social, que engloba aspectos culturais e ambientais. No caso de Arembepe: é caracterizada pelo IBGE como uma zona urbana isolada, que teve seu crescimento em torno de uma aldeia de pescadores o turismo pode ser caracterizado a partir das práticas de veraneio, como também as práticas de um turismo em massa, sendo deste modo, frequentada por turistas e visitantes de municípios circunvizinhos e de Salvador, principalmente nos finais de semana. A mesma enfrenta vários problemas em relação ao esgotamento sanitário, apesar de terem sido realizadas algumas, com recursos do próprio poder público municipal durante os anos de $2008 \mathrm{e}$ 2010. Em relação ao setor informal, a localidade engloba muitas unidades econômicas de trabalhadores por conta própria. Onde, a influência desta economia é utilizada pela atividade turística. Por isso, torna necessária a compreensão econômica do setor informal, pois muitas das vezes é esse setor diretamente afetado pela atividade de maneira que a população se utiliza dessa forma de trabalho como complemento da renda familiar, primeiro emprego devido à dificuldade no mercado trabalho formal. Na localidade apresenta um setor organizado do comércio informal, através da venda de itens alimentícios na feira, e mercado pode estar relacionado a atividades de baixo nível de produtividade exercidas pelos trabalhadores independentes. Além do comércio localizado na feirinha, há presença de vendedores ambulantes principalmente no centro comercial da localidade próxima a praia, que caracterizam-se através da venda dos produtos em carinhos de mão. Conclui-se que, o setor comercial informal da localidade está diretamente dependente da atividade turística, onde as vendas apresentam aumento nos períodos de alta estação (Verão). Entretanto durante os períodos de baixa estão os comerciantes informais utilizam-se de estratégias para manter aquecimento das vendas estratégias como: a diminuição no preço dos produtos a serem vendidos, a compra de produtos para durarem as duas estações (alta e baixa) entre outras, a vista que, na maioria dos casos e nesse tipo de trabalho que se retira a renda mensal familiar. A localidade de Imbassaí: está situada também no litoral da Bahia, pertencente ao município de Mata de São João-BA na faixa costeira do Oceano Atlântico e na foz do Rio Imbassaí. Após a ampliação da BA-099 - Linha Verde, que contribuiu com o rápido acesso à localidade o fluxo turístico sofreu um aumento, onde o perfil dos turistas são pessoas oriundas de outras partes da capital do estado e até do exterior. A mesma está para voltada ao turismo de luxo, onde ao longo do seu território apresenta várias pousadas e empreendimentos hoteleiros de luxo, por exemplo, o Grand Palladium Imbassaí Resort. A localidade apresenta variados estabelecimentos de funcionamento informal que contribuem para e economia da mesma. Entretanto não se é permitido a venda de mercadorias de qualquer natureza na praia ou na parte central da localidade. Com isso, os trabalhadores informais apresentam completa insatisfação com o poder público, devido a fiscalização e apreensão das mercadorias. A fiscalização do seu comércio se dá mediante um alvará de funcionamento entregue tanto na prefeitura na sede do município como na subprefeitura na própria localidade. Outro modo de controle se dá a partir "do controle do uso do solo". Os trabalhos informais encontrados na localidade estão situados próximo ao leito do rio Imbassaí, que ocorre através do passeio em pequenas embarcações, além do serviço de transporte sobre duas rodas (moto-taxi). 


\section{CONSIDERAÇÕES FINAIS (ou Conclusão)}

Durante a pesquisa percebeu-se que: as localidades de Arembepe e Imbassaí encontramse em processo de modernização do espaço urbano, através de incentivos do poder público, com a introdução de determinados aparelhos urbanísticos, que vem possibilitando o desenvolvimento da atividade turística na região. Sendo importante ressaltar que a sua economia informal está da estreitamente subordinado ao setor formal e seu desenvolvimento é fortemente dependente desse último, justificado através das dificuldades de emprego nos setores formais, onde a informalidade torna-se uma possibilidade de inserção no mercado de trabalho. Nas localidades apesar das dificuldades encontradas nas coletas de dados, é possível perceber que a atividade turística influencia diretamente nas economias informais urbanas, onde grandes partes dos seus trabalhadores são residentes das mesmas. Sendo o trabalho informal uma oportunidade de manteremse ativos no mercado de trabalho, a vista que é através desse exercício que muitos retiram a principal renda do familiar. Para além, a atividade turística apresenta-se como uma alternativa para o desenvolvimento presente e futuro das localidades. No entanto, esse desenvolvimento não é simples, pois são necessários trabalhos de planejamento que proponham à maximização de impactos positivos que o turismo pode gerar para o desenvolvimento do comércio local. Onde, segundo BOULLON (2002) o espaço turístico é consequência da presença e distribuição territorial dos atrativos turísticos que, não devemos esquecer, são a matéria-prima do turismo. Estes elementos pertencentes ao patrimônio turístico, juntamente com os empreendimentos e a infraestrutura turística, são suficientes para definir o espaço turístico no território em que estão sendo inseridos. Também é importante ressaltar que, o modelo econômico. Que pode favorecer com que os gestores públicos tenham uma visão econômica da atividade turística, possibilitando a elaboração de políticas públicas para o desenvolvimento dessa atividade.

\section{REFERÊNCIAS}

ANDRADE, Manuel Correia de. Geografia econômica. 12. Ed. São Paulo: Atlas, 1998. BOULLÓN, R. C. Planejamento do Espaço Turístico. Bauru, SP: EDUSC, 2002. CRUZ, Rita de Cássia Ariza da. Introdução a Geografia do Turismo. São Paulo: Roca 2 ed. 2003.

SANTOS, Telma Maria Sousa dos. Turismo e urbanização em espaços litorâneos: um olhar sobre Praia do Forte - Bahia. Feira de Santana, BA: UEFS, 2013.

TOMAZINI, S. Emprego informal e trabalho por conta própria: um estudo da diversidade de manifestação do problema da falta de emprego no Brasil. Dissertação (mestrado em economia) Unicamp, Campinas, 1995. 